\title{
TUBERCULOSIS IN 1996: A VIEW FROM GENEVA
}

Michael H. Levy

Global Tuberculosis Program

World Health Organization

Geneva, Switzerland

uberculosis has received renewed attention during the past five years, both as the focus of public health policy and from clinical perspectives. This article outlines global priorities for TB control, identifies the implications for Australia, and acknowledges recent Australian developments in TB control, both at home and more widely in the Asia-Pacific region.

\section{MAJOR GLOBAL PRIORITIES}

In 1993 the World Health Organization (WHO) called on health planners throughout the world to recognise TB as a global emergency.

The highest priority for global TB control is to persuade health authorities throughout the world to take a systematic approach to the TB problem. This requires a commitment by governments to the allocation of resources for drug supplies, and to the introduction of information systems for monitoring treatment outcomes. Above all, directly observed treatment, short-course (known as DOTS) must be widely accepted and implemented.

There are major barriers to the achievement of global TB control:

Population-based estimates of the acceptance of DOTS vary from 10 to 30 per cent - too low to prevent emergence of drug-resistant TB.

The development of new anti-tuberculosis measures which are cheap enough for resource-poor countries appears to be an unlikely prospect.

In many countries clinicians fail to make use of existing diagnostic methods, and fail to differentiate infectious cases from non-infectious cases.

In many parts of the world poor treatment leads to chronic disease.

The need for expertise in TB control far outstrips the availability of qualified personnel.

\section{IMPLICATIONS FOR AUSTRALIA}

While Australia has a low incidence of TB, global population mobility poses a continuing risk for the importation of TB from countries with higher incidence (i.e. most of the rest of the world). It is therefore essential for Australia to have a TB control program which provides a basis for managing this risk.

Many of the principles of TB control are the same for highincidence and low-incidence countries. The essential components of TB control programs are:

accurate diagnosis of TB cases;

effective treatment; and

evaluation of TB control programs.

\section{Diagnosis}

Sputum microscopy remains the best test for determining whether individual cases pose a public health risk for the spread of disease to others, and for deciding whether efforts should be made to trace contacts. Sputum culture and sensitivity testing are the appropriate investigations for patient management and program monitoring.

\section{Treatment}

All treatment - every dose during the first two months of treatment - must be fully supervised. This is the basis of directly observed therapy. Cases must be followed through to the end of treatment, assessed and categorised according to treatment outcome.

The global target is to cure 85 per cent of identified cases. Australia should be able to achieve this target, but treatment outcome information is not reported.

\section{Evaluation}

In addition to monitoring treatment outcome, surveillance of drug-resistance patterns of TB bacilli is an important method of monitoring TB control activities. Evaluation of TB control should pay specific attention to communities which are at high risk of transmission, such as the prison population. Timely monitoring of TB notifications is essential. Reporting to the WHO provides a mechanism for Australia to gauge its performance in TB control against that of other countries. This is important if Australia is to maintain its pre-eminent position in TB control among all the nations of the world. Australian surveillance on TB is reported to the WHO by the Commonwealth Department of Health and Family Services.

\section{HISTORY OF AUSTRALIAN TB CONTROL PROGRAMS}

Historically, TB control has been the responsibility of the Commonwealth. In 1976 public health aspects of TB became a State/Territory responsibility. From 1976 to 1991, ad hoc meetings of individuals identified as 'State Tuberculosis Directors' were held to coordinate national TB control efforts, but it was only when the National Health and Medical Research Council (NHMRC) convened a working party in 1992 that TB control was once more formally acknowledged as an issue of national significance.

During the years 1976-1991, the predominant concerns of 'State Directors' was the issue of pre- and post-migrant screening. This recognised that the burden of TB in Australia was due to infection acquired overseas; Australian residents born overseas have a notification rate 20 times that of people born in Australia'.

\section{RECENT DEVELOPMENTS}

Since 1992 a wide range of TB control activities has been developed in Australia, supported by Commonwealth and State/Territory health departments, non-government organisations and the professions.

The most important has been the development of guidelines. Several States and Territories have produced guidelines for TB control and the diagnosis and management of TB cases. The NSW Health Department has issued a second edition of the publication, Controlling Tuberculosis in New South Wales ${ }^{1}$, and the Victorian and Northern Territory health departments have published similar guidelines ${ }^{2}$. The NHMRC is expected to release national guidelines in 1997.

While the Commonwealth, State and Territory health departments have responsibility for TB control, Australia has a long and proud tradition of participation by nongovernment organisations in important activities which support the control of TB. Over the past 10 years the Community Health and Anti-tuberculosis Association 


\section{TUBERCULOSIS IN NSW: STATUS AND PRIORITIES}

Timothy Heath $h^{1,3}$, Meg Winks', Christine Roberts ${ }^{3}$, Anthony Capon ${ }^{1}$

1. Western Sector Public Health Unit

2. Formerly AIDS/Infectious Diseases Branch, NSW Health Department

3. National Centre for Epidemiology and Population Health, Australian National University, ACT

$\mathrm{T}$

his article provides a profile of tuberculosis occurrence in

NSW, based on an analysis of surveillance data for 1995 .

TB has re-emerged globally as a major threat to human health. It now causes more deaths worldwide than any other infectious disease, and is responsible for a quarter of preventable adult deaths worldwide ${ }^{1,2}$. Abetted by HIV/AIDS, the brunt of TB disease is borne by the developing world ${ }^{3}$. However, the USA, the UK and several European countries have also encountered increasing rates of active TB ${ }^{4}$. Outbreaks of multi-drug-resistant TB in urban and hospital settings in the USA have posed the additional threat of untreatable disease ${ }^{5}$. While TB rates in NSW (as in most other Australian States) have remained among the world's lowest, there is no room for complacency.

\section{METHODS}

NSW TB notification data for 1995 were obtained from the NSW Health Department's Infectious Diseases Surveillance System (IDSS) database for notifiable infectious diseases. Australian Bureau of Statistics (ABS) 1991 census data were used to calculate disease rates by country of birth and Aboriginality. All other rates were calculated using ABS estimated mid-year populations.

\section{Definitions}

In NSW, the surveillance definition of active TB (for notification purposes) is:

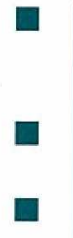

signs and symptoms compatible with pulmonary $\mathrm{TB}$, and an abnormal, unstable chest x-ray, (i.e. one which suggests disease progression); $O R$ signs and symptoms compatible with extrapulmonary TB; OR evidence of disease where treatment with two or more anti-TB drugs have been prescribed; OR
TABLE 1

TUBERCULOSIS NOTIFICATIONS BY SITE OF DISEASE, NSW, 1995

\begin{tabular}{|llrr|}
\hline Site of disease & & $\begin{array}{r}\text { No of } \\
\text { cases }\end{array}$ & $\%$ \\
\hline Pulmonary & Respiratory & 240 & $(52)$ \\
& Primary & 20 & $(4)$ \\
\hline Extrapulmonary & Genito-urinary & 22 & $(5)$ \\
& Bone/joint & 20 & $(4)$ \\
& Gastrointestinal & 9 & $(2)$ \\
& CNS/meningitis & 4 & $(1)$ \\
& Miliary & 4 & $(1)$ \\
& Other (incl. lymphatic) & 119 & $(26)$ \\
\hline Not specified & & 24 & $(5)$ \\
\hline Total & & 462 & $(100)$ \\
\hline
\end{tabular}

isolation of Mycobacterium tuberculosis complex organisms from a clinical specimen; OR demonstration of acid fast bacilli (AFB) in a clinical specimen from a person with signs and symptoms compatible with pulmonary TB.

A new case of active TB is an individual who has not previously received anti-TB chemotherapy for more than one month. A reactivated case is one where active TB has recurred more than one year after completion of therapy for proven disease.

Treatment default is defined as interruption of treatment for more than two months, after completing the first month of chemotherapy.

\section{RESULTS}

\section{Disease classification and site}

By August 1996, 462 cases of active TB had been reported in NSW with onset in 1995 ( $7.5 / 100,000$ population). Of these, 334 notifications ( 72 per cent) were new cases, 34 ( 7 per cent) were reactivated cases, and for 95 ( 21 per cent) a case classification was not specified. The principal anatomical site of disease was extrapulmonary for 178 notifications (38 per cent) (Table 1 ).

Continued on page $136 \mathrm{D}$
(CHATA) has supported TB-related research in Australia (through the Harry Windsor Scholarship scheme) and TB control activities in Asia - particularly Vietnam. The Public Health Association of Australia convened the National Tuberculosis Conference in November 1994 and is planning a second meeting during 1997.

CHATA's support of TB control activities in Asia is part of Australia's increasing recognition of its regional responsibilities in TB control. Since 1995, the Australian Government, through the Australian Agency for International Development, has supported TB control efforts in Indonesia and throughout the Pacific region under the World Health Organization's Global Tuberculosis Program. Australian-trained public health professionals are guiding TB control activities in Indonesia, China and
Mongolia. Australians have been prominent in working with refugees in Hong Kong and Vietnam; guidelines for control of TB among refugees and displaced persons are being devised through the Macfarlane Burnet Centre for International Health; and economic analyses of TB control activities in China are being undertaken through the National Centre for Epidemiology and Population Health at the Australian National University in Canberra. Australian laboratories are participating in a global network for the monitoring of Mycobacterium tuberculosis drug resistance.

1. Dwyer B. What we should be doing about tuberculosis in Australia. Med J Aust 1996; 164:62-63.

2. Gilbert GL. Multi-drug-resistant tuberculosis: prevention is better than cure. Med J Aust 1996; 164:121-124.

3. Hargraves J. Tuberculosis notifications in Australia, 1993. Commun Dis Intell 1995; 19:334-343. 